\title{
SENDING EN DIE OU TESTAMENT
}

\section{DR. H. G. VAN DER WESTHUIZEN}

A. Vir baie jare is die verband tussen sending en Ou Testament gesien net in die sin van sending IN die Ou Testament. Hiervolgens word daar in die $\mathrm{Ou}$ Testament gesoek na sogenaamde sendinggedagtes of -tekste, -gedeeltes.

\section{Die Sendingverwagting in die Ou Testament.}

a. Die onderwerp van die $\mathrm{Ou}$ Testamentiese sendinggedagte het eers so laat as 1880 in wetenskaplike aktualiteit getree en wel deur prof. E. Riehm ${ }^{1}$ ).

b. Die Ou Testament was gewoonlik beskou as ,partikularistiese boek van weinig betekenis in sendingopsig ${ }^{2}$ ). Omdat die jongste neiging in die Bybelse fundering van die sending is om nie so veel na bepaalde tekste te verwys nie,, en ook om meerdere insig in die Bybel wat die sendingsaak betref, word dit al meer sinvol om die Ou Testament ook as ,sendingboek" te beskou ${ }^{3}$ ).

c. Daar is 'n paar plekke in die Ou Testament wat dikwels aangehaal word as van sendingbelang. Ons beperk ons tot twee van die bekendstes.

aa. Jesaja 42:1: ". . . Hy sal die reg na die nasies uitbring." Jesaja 40-55 as geheel word gewoonlik as een van die „missionêre hoogtepunte" in die Ou Testament genoem ${ }^{4}$ ). Hierby saam kan ook gedink word aan Jes. 66:18vv.

Daar bestaan die gedagte dat Israel, hoe dan ookal, ,sending" moes doen en dit verwaarloos het: „Israel was onwillig om hierdie opdrag te vervul en het steeds weer van die uitverkiesing, wat 'n genadegawe van die Here is, wat 'n opdrag tot werkdadige geloof in God is, 'n passiewe uitverkorenheid gemaak. Daarom moes die tweede Jesaja ook nog van 'n ander Kneg predik, naamlik die Lydende Kneg van die Here (Jes. 53). Ook die onwil van Israel ten opsigte van hulle roeping om met die heilsboodskap in die wêreld in te tree, moes deur hierdie Kneg versoen word"s). Die verwaarlosing van hulle sending word dan onder andere as grond geag vir die ballingskap. Dieselfde „motief” vind mens in

1) R. Riehm, „Der Missionsgedanke im Alten Testament”, Alg. MissionsZeit,schr. 1880, bl. 453-465. Vgl. hieroor dr. D. J. Bosch, Sendingperspektief in die Ou Testament, Ned. Geref. Teologiese Tydskrif, Desember 1961, bl. 285.

2) Vgl. dr. D. J. Bosch, a.w., bl. 285.

3) Vgl. dr. D. J. Bosch. Kalleidoskoop van die na-oorlogse Sendingwetenskap, Lux Mundi 1. Sendingwetenskap vandag - 'n Terreinverkenning, N.G. Kerk-Boekhandel, 1968, bl. 20.

4) J. Blauw, Gottes werk in dieser Welt, München, 1961, bl. 31vv.

5) Dr. B. J. van der Merwe. Gedagtes uit die Prediking van die tweede Jesaja, Die Hervormer, Oktober 1957, bl. 9. 
die Nuwe Testamentiese tyd, naamlik dat die christene vervolg word en dit bydra om die evangelie te versprei ${ }^{6}$ ). In 'n mate vind dit ook tydens die Hervorming plaas ${ }^{7}$ ). God se hamer is soms nodig om sy kerk te laat versprei oor die wêreld.

Die sending van Israel word deserdae regtens „,sentripetaal ${ }^{3}$ ) genoem: , . . . dit wil sê Israel word nie uitgestuur om sendingwerk onder die volke te doen nie. Israel is 'n getuie deur sy swye (Jes. 42: 18)"'). Hierdie sentripetale sending word nie deurbreek met Deuterojesaja nie. Deuterojesaja stel juis dat vanweë die verwaarlosing van die sentripetale sending ${ }^{10}$ ) daar nou 'n visie gekom het, 'n verwagting van 'n "sentrifugale" sending. Volgens Jes. 42:4: „... en die eilande wag op sy leer"11), wag die eindes van die aarde ${ }^{12}$ ) op die lig wat die Kneg sal „uitbring"13). Maar hierdie is toekomstig (eskatologies). Die wêreld „wag” — nie bewustelik nie, maar soos die ganse skepping volgens Rom. 8:19 wag. Soos die Messiaskoms in die Ou Testament die sinvolheid is van die geskiedenis waarop die wêreld ,wag", só is die sendingkoms die realisering waarvolgens hierdie geskiedenis-doel (die wag,) bereik word. Deuterojesaja is dus nie 'n ,uitsondering"14) in die Ou Testamentiese gedagtegang nie, maar verlengstukvisie op die program reeds in Gen. 12:2 gegee.

bb. Jona. Sommige sê: „Die boek Jona vorm in hierdie verband 'n belangrike uitsondering in die Godsopenbaring van die $\mathrm{Ou}$ Testament; hier is vir die eerste maal baie duidelik sprake van die sending (missie) van 'n profeet van Jahwe na 'n heidense

6) Vgl. P. S. Dreyer, Die Onwillige Kerk, Almanak 1957, bl. 61: „Hierdie vervolging (van die eerste christene) was so kwaai dat talle Christene uit Jerusalem moes vlug. Hierdie ramp lei egter tot die eerste sendingwerk (Hand. 8, 11:19-30), sodat die Evangelie in Samaria verkondig word, die hofdienaar van Ethiopië (Abesinië) tot bekering kom en die evangelie diep in Afrika indra, die gemeente van Antiochië gestig word en so meer."

7) Die onstaan van die invloedryke Nederlandse Geloofsbelydenis in 1561 bv. was as gevolg van vervolging. Vgl. dr. J. Koopmans, De Nederlandse Geloofsbelijdenis, Uitgeversmaatskappij Holland te Amsterdam, in het jaar MCMIL, bl. 7 .

8) Bengt Sundkler het in 1937 die feit deur hierdie benaming die eerste keer duidelik gestel. Vgl. dr. D. J. Bosch, a.w., N.G.T.T. Desember 1961, bl. 295 veral voetnoot 26 .

9) Prof. Hugo du Plessis. 'n Banier van die Volke, Pro Rege Pers, Potchefstroom 1963, bl. 162.

10) Hugo du Plessis, a.w., bl. 157: .Israel was uitverkies om 'n getuie vir die nasies te wees (Jes. $43: 10,12,21$ ) maar was hierin 'n mislukking."

11) Vgl. bv. ook Jes. 51:5.

12) "Eilande" beteken „wye wêreld", vgl. Jes. 40:15; 41:1; 49:1; ens. "Eilande" of "wye wêreld" dra die betekenis van "heidene" - Vgl. Arend Th. van Leeuwen, Christianity in World History, bl. 64 e.a.

13) Die woord .,josl" is in die hifil (..laat"), futurum (,sal"), derde persoon. enkelvoud (,hy") vorm. Vgl. Köhler-Baumgartner, Lecsiscon in Veteris Testament Libros, S.V. Vgl. ook D. J. Bosch, a.w., N.G.T.T. bl. 294, voetnoot 24.

14) Vgl. dr. D. Crafford. Wêreldsending en Wêrelddiakonaat, D.D. proefskrif, Universiteit van Pretoria, ,1966, bl. 89. 
volk"15). Jona is egter nie uitsondering in die Ou Testamentiese gedagtegang nie, en aan die anderkant ook nie 'n voorbeeld van „sending" nie. Dit is nie 'n voorbeeld van sending nie omdat alomaankondiging is, dit wil sê die volle evangeliese boodskap, en nie net 'n oordeelsaankondiging nie, wêreldwyd, nie spesifiek 'n bepaalde volk nie. In Jona gaan dit egter om 'n bepaalde boodskap, met 'n bepaalde geleentheid aan 'n bepaalde stad.

Jona is nie 'n uitsondering in die Ou Testamentiese gedagtegang nie omdat dit profesie is van Christus wat vanweë sy verkeer in die ingewande van die dood die heil laat uitgaan na die wêreld. En hierdie profesie van die eskatologiese sendingverwagting is nie vreemd aan die Ou Testament nie ${ }^{16}$ ).

d. Hoewel heidene en sommige Ou Testamentici miskien die Ou Testament vanuit die Ou Testament self wil verstaan, verstaan die christene die Ou Testament alleen vanuit die Nuwe Testament ${ }^{17}$ ). Net soos die inhoud van die Ou Testament vanuit die Nuwe Testamentiese openbaring, Christus, is $\left.{ }^{18}\right)$, só is sending ook voluit inhoud van die Ou Testament maar in profetieseskatologiese sin.

\section{Die Sendinggroeping in die Nuwe Testament.}

a. Die wending in die Bybel waarmee die daadwerklike (dadelike) sendingtaak 'n aanvang neem, is nie die lyn tussen Ou. en Nuwe Testament nie ${ }^{19}$ ). Die sesuur lê tussen Christus se dade vóór sy hemelvaart en dié na sy hemelvaart vanaf die koms van die Heilige Gees; ${ }^{20}$ ) die aanvang van die verwagte eskatologie. „So wäre es unmöglich, einen neutestamentlich sinnvollen Begriff des ,Eschatologischen' etwa nur auf das letzte stadium der Parusie anzuwenden. Eschatologisch heisst: ,endzeitlich'. Die Endzeit ist die Zeit der Welt, der Menschheitsgeschichte, der Geschichte aller Menschen, der im Tod Jesu ihr Ende schon gesetzt ist und nur noch diesem ihr schon gesetzten Ende entgegen weiterlaufen kann. Im Osterereignis als dem Anheben des neuen Kommens Jesu Christi in der Offenbarung des in einem Leben und Sterben Geschehenen wird auch das offenbar, dass die der Welt, aller: Menschen, uns selbst gelassene Zeit nur noch Endzeit - ihrem ihr gesetzten Ende entgegenlaufende Zeit - sein kann. In diesem Sinn ist das Osterereignis das ursprünglichs, weil erste eschato-

15) D. J. Bosch, a.w., N.G.T.T. bl. 294.

16) Vgl. J. Blauw, a.w., bl. 36vv; $41 \mathrm{vv;} 47,38 \mathrm{vv}$.

17) 2 Kor. 3:13vv. Vgl. Rolf Rendtorff, Das Werden des Alten Testaments, „Biblische Studien” Heft 26, 1959. Vgl. J. P. Oberholzer, Christusverkondiging en die Ou Testament, Hervormde Teologiese Studies, Oktober 1963, bl. 1vv.

18) Lukas 24:27; Hand. 8:35; Lukas 16:31; e.a.

19) Vgl. J. Blauw, a.w., bl. 92vv.

20) Vgl. Hand. $1: 1,2$. 
logische Ereignis. Die Mitteilung des Heiligen Geistes wie das Kommen Jesus Christi in der noch dauernden Endzeit - wie wir noch sehen werden: Die mit dem Heiligen Geist und durch ihn gegebene Verheissung, von der Gemeinde, aber mit der Gemeinde die Welt, in der sie eistiert und in der sie ihre Sendung hat, in der zu Ende gehenden Zeit leben darf"21).

b. Net soos die bestaan van die kerk Apostelêr van karakter is, so is die Nuwe Testament karakteristiek-apostolêr ${ }^{22}$ ).

c. Sending pas in die algemene skema van die Bybel naamlik, belofte: vervulling.

d. Sonder die Nuwe Testament word sending nie verstaan nie. Sonder die Ou Testament word sending nie reg verstaan nie. Sonder die Ou Testament is die Nuwe Testament uit perspektief: "The Old Testament . . gives perspective to the New Testament ....23)

B. Die verhouding sending en Ou Testament kan ook in 'n ander verband, naamlik sending VAN die Ou Testament gesien word. Die Ou Testamentiese sending is dié waarheen die $\mathrm{Ou}$ Testament op pad is, dié ná die Ou Testament-tyd. Hiervolgens het die Ou Testament ' $n$ plek in die sending as die vórsin van Gods Woord. Die verhouding kan dus geformulleer word as die Ou Testament in sending. Want sending is Woordverkondiging - Nuwe en Ou Testament in regte beligting. Die noúkeuriger vraag is egter wat is dié Woord wat verkondig moet word in die sending? Karl Barth onderskei die Woord in drie gestaltes: Die Verkondigde Woord, die Geskrewe Woord, die Geopenbaarde Woord ${ }^{24}$ ) Hoewel die Verkondigde Woord (prediking) kom uit die geskrewe Woord (Bybel) en lei na die geopenbaarde Woord (Jesus Christus) en daar dus 'n onverbreekbare eenhied is, is die vraag tog: watter Woord is die inhoud van die sending? Want dit kan gebeur dat die sending Christus verkondig maar nie soos die Bybel Christus openbaar nie. Dit kan straks gebeur dat die sending die kerk se boodskap as verkondigde Woord as inhoud het wat bes moontlik verskil van die geskrewe Woord.

Die Woord wat in die sending verkondig moet word is die geskrewe Woord. Só 'n verkondiging word self verkondigde Woord en Christus wat self geestelik ook teenwoordig is, neem dáánin deur die Gees $^{25}$ ) geopenbaarde gestalte aan in die geloof

21) Karl Barth, K.D. IV 111, 1, 340-341.

22) Vgl. die volgende vir sending in die Nuwe Testament: Ferdinand Hahn, Das Verständnis der Mission im Neuen Testament, Neukirchener verlag 1963. Vgl vir 'n verdere oorsig oor bibliografie: D. J. Bosch, Kaleidoskoop, bl. 16vv.

23) G. C. Oosthuizen, Post-Christlanity in Afrika, A theololgical and anthropological study, T. Wever, Stellenbasch, 1968, bl. 162.

24) Karl Barth, Kírchliche Dogmatik, 1, 1, 89.

25) 1 Kor. 12:3; Matthelis 16:17. 
van die wordende gemeente. Sending is dus Woordverkondiging, nie Sakramentsbediening nie $^{26}$ ), nie barmhartigheidsdienste nie $^{27}$ ), nie enigiets anders as Woordverkondiging nie.

Die inhoud van dié verkondiging is dus die inhoud van die Nuwe en van die Ou Testament - wat Jesus Christus is ${ }^{28}$ ). Vanuit Jesus Christus, die openbaring van $\mathrm{God}^{29}$ ), ken ons die Drieënige God wat die enigste Skepper, Onderhouer en Verlosser is.

\section{Sending is die aankondiging van die Onbekende Woord.}

Wanneer die Woord verkondig word in die gemeente - is dit sending? Nee! Dit is pastoraat. Die verskil tussen die sendingverkondiging en die kerklike verkondiging (om nou dit maar só te noem) is nie inhoud nie, nie in omvang nie, maar in voortgang. In die kerklike verkondiging gaan dit om gelowiges sodat hulle ,,in die kennis van God mag groei" ${ }^{30}$ ), opgebou word ${ }^{31}$ ), ,na die volmaaktheid voortgaan sonder om weer die fondament te lê . . . "32). Dié verskil word reeds deur die Nuwe Testament geïmplimenteer met die gebruik van verskillende woorde: "... Matthäus hat zwischen kërussein und didaskein konsequent unterschieden, das erste bezieht zich auf die Botschaft von der Gottesherrschaft, das zweite auf die Auslegung des Gesetzes ... Dabei ist zunächst zu beachten, dass euanggelion bei Matthäus überhaupt nur in der Verbindung mit kërussein gebraucht wird"33).

Wanneer De Wet spesifiek die gestaltes van die Woordverkondiging vasstel, sê hy: „Die gestalte van die kerklike verkondiging onder hulle wat nog nie die evangelie gehoor het nie, heet in die Nuwe Testament kerugma"34).

Daarby merk hy op: „Euangelion Euangelidsethai en Euangelistes is eintlik die enigste sinonieme wat ons in die Grieks van die Nuwe Testament aantref vir Kerugma, kerussein en

28) 1 Kor. 1:17.

27) Hand. 6:2 slaan wel nie net op sendingwerk nie maar eerstens op Woordbediening binnekerklik. Soveel te meer dan is dit van toepassing op die sendingveld!

28) 1 Kor. 2:2, Hand. 8:35; Lukas 24:27.

29) Johannes 14:9; Kolossense 1:15vv.

30) Kolossense 1:10.

31) Hand. 20:32; Kol. 2:7.

s2) Hebreërs $6: 1$.

s3) Ferdinand Hahn, a.w., bl. 104/5. Vgl. L. Floor. In Dieselfde Spore, Die Evangelis, 1964, bl. 73 waarvan B. Spoelstra (In die Skriflig, Jaargang 2. Nr. 8, November 1968 bl. 35) opmerk: „Dit is interessant dat Lukas die missionêre prediking (kérussein) onderskei van spontane evangelieverkondiging deur lidmate (evangelizestai en lalein ton logon theo)".

34) J. I. de Wet, Die Kerklike Verkondiging in die Huidige Tydsgewrig, bl. 12. 
keruks"35). Hierteenoor stel De Wet: „Uit die oorsig van die woorde didaskalos, didache en didaskein word dit vir ons duidelik dat ons hier te doen het met sistematiserende verduideliking van die aangekondigde heil binne die gemeenskap van hulle wat reeds die evangelie gehoor en geglo het" ${ }^{36}$ ).

Ons kan dus onderskei tussen stigtingsprediking (kêrugma sendingprediking) en stigtelikeprediking (didaskalia - kerklike prediking).

Die stigtingsprediking of sendingprediking, noem ons hier - aankondiging om dit te onderskei van verkondiging. Die woord aankondiging onderstreep ook die gedagte dat dit 'n onbekende Woord is, a verbum externum wat van buite, van Bo, na ons toe aankom en nie ' $n$ woord wat in die mens self opkom nie.

Die aktuele vrae so dikwels in die geskiedenis gevra: wat is die plek van die sending in die Nuwe Testament ${ }^{37}$ )? En die nog moeiliker vraag: wat is die plek van die sending in die Ou Testament $^{38}$ ), behoort eintlik ook andersom gevra te word: Wat is die plek van die Ou Testament en die plek van die Nuwe Testament, die plek van die Bybel, in die sending ${ }^{39}$ ). Die volle Bybelse boodskap as onbekende Woord is die intensiewe vorm van die alomaankondiging in die sending.

As een voorbeeld vir die waarde van die Ou Testament in die sending onder die bantoe noem ons die Ou Testamentiese Gods. begrip wat in die bantoereligie die tradisionele modimobegrip kan ,sekulariseer" in die lig van die Nuwe Testamentiese. Omdat die bantoe se modimobegrip 'n skakelilng-struktuur ontologie is, sal die direkte stel daarvan onder die blote lig van die Nuwe Testament eerder 'n verheidensing van die Nuwe Testament teweeg bring onder die waan van 'n verchristeliking van die bantoegodsdiens. So het 'n bantoe-christen dan gesê dat sonder die Ou Testament sou die God van die Nuwe Testament vir hom 'n vreemde Europese God wees ${ }^{40}$ ).

35) J. I. de Wet, a.w., bl. 13. Vgl. ook Gerhard Kittel, Theologisches Wörterbuch Zum Neuen Testament, 11, 715, 31..

so) J. I. de Wet, a.w., bl. 21.

87) Vgl. bv. Ferdinand Hahn, Das Verständnis der Mission im Neuen Testament, Neukirchener Verlag, 1963.

38) Vgl. prof. Hugo du Plessis, 'n Banier van die Volke, Pro Rege Pers, Potchefstroom 1963, veral Hoofstuk XV: Die Sendinggedagte in die Ou Testament, bl. 178-185.

39) H. Bergema, Het Oude Testament en de Zending, Vox Theologica, Jodendomnummer, 9e jaar $\mathrm{Nr}$. 4, Maart 1938, bl. 112 vv.

10) H. Bergema, a.w., bl. 117 . 
Die beste voorbeeld vir die onmisbare plek van die Ou Testment in die sending, is by die sending onder Israel ${ }^{41}$. Om alleen die Nuwe Testament as Woord van God aan Israel te verkondig, sou as negering van die Ou Testament totaal verkeerd wees. Jesus sê: „Julle ondersoek die Skrifte (Ou Testament) . . . en dit is die wat van My getuig." (Joh. 5:39). Hoe totaal verwoestend sal die sendingpoging nie misluk as in plaas van die sluier oor die Ou Testament te verwyder vir die volk van die Ou Testament, die Ou Testament self verbygegaan word? „Alleen de Christus, die in het Ou Testament beloofd is, de Christus der Schriften, is de ware Christus"42). Filippus vra juis aan die kamerling van Ethiopië „Verstaan u wat u lees?” (Hand. 8:30). Die Ou Testamentiese kennis is voorwaarde voordat die weg tot begrip aangetoon kan word. (Hand. 8:31). „Filippus het . . . van hierdie Skrif (Ou Testament) af begin en die evangelie van Jesus aan hom verkondig." (Hand. 8:35). Só het Jesus immers self met die Emmausgangers gewandel en aan hulle "... van Moses en al die profete af (Ou Testament) ... uitgelê in al die Skrifte (Ou Testament) die dinge wat op Hom betrekking het." (Lukas 24:27).

Die verband tussen Ou Testament en sending kan op enige wyse beslen word maar sal in die lig van die Nuwe Testament blyk integraal te wees.

41) Deserdae praat die Angelsaksiese wêreld liewers van ,approach to the Jews", en die Nederlanders van ,gesprek met Israel", en die Duitsers van „diens aan Israel”. - Vgl. "Rapport Raad vir die Arbeid onder Israel, Bylae tot die Agenda van die Alg. Kerkverg. van die Ned. Hervormde Kerk van Afrika, 1967, bl. 03.

42) H. Bergema, a.w., bl. 116 . 